\title{
Overexpression of Derlin 3 is associated with malignant phenotype of breast cancer cells
}

\author{
MASAHIRO SHIBATA ${ }^{1}$, MITSURO KANDA ${ }^{2}$, HARUYOSHI TANAKA ${ }^{2}$, SHINICHI UMEDA $^{2}$, \\ TAKASHI MIWA ${ }^{2}$, DAI SHIMIZU ${ }^{2}$, MASAMICHI HAYASHI ${ }^{2}$, TAKAHIRO INAISHI ${ }^{1}$, \\ NORIYUKI MIYAJIMA ${ }^{1}$, YAYOI ADACHI ${ }^{1}$, YUKO TAKANO ${ }^{1}$, KENICHI NAKANISHI $^{1}$, \\ DAI TAKEUCHI $^{1}$, SUMIYO NODA ${ }^{1}$, YASUHIRO KODERA ${ }^{2}$ and TOYONE KIKUMORI ${ }^{1}$ \\ Departments of ${ }^{1}$ Breast and Endocrine Surgery (Surgery II), ${ }^{2}$ Gastroenterological Surgery (Surgery II), \\ Nagoya University Graduate School of Medicine, Showa-ku, Nagoya 466-8550, Japan
}

Received February 9, 2017; Accepted June 26, 2017

DOI: 10.3892/or.2017.5800

\begin{abstract}
Breast cancer (BC) is the most common malignant tumor among women worldwide. Development of novel molecular targets is important to improve prognosis of $\mathrm{BC}$ patients. Derlin 3 (DERL3) gene is a member of derlin family, and its coding protein is critical to the endoplasmic reticulumassociated degradation mechanism. However, its oncological role in breast cancer remains unclear. This study evaluated DERL3 expression and function in BC. We analyzed DERL3 mRNA in 13 BC and two non-cancerous cell lines, and explored effects of DERL3 knockdown on BC proliferation, invasion and migration. We also evaluated correlation of DERL3 mRNA expression levels with clinicopathological factors and prognosis in 167 BC patients. DERL3 mRNA expression was detected in five (38\%) BC cell lines. Inhibiting DERL3 expression significantly decreased proliferation and invasion in BC cells. Specimens from patients with lymph node metastasis had higher DERL3 mRNA expression than those without $(\mathrm{P}=0.030)$. Patients in the highest quartile for DERL3 mRNA expression $(\mathrm{n}=42)$ were more likely to experience shorter overall survival than other patients $(\mathrm{P}=0.032)$. These findings indicate that DERL3 promotes malignant phenotype in BC cells. DERL3 may serve as a potential prognostic marker and therapeutic target for $\mathrm{BC}$.
\end{abstract}

\section{Introduction}

Breast cancer $(\mathrm{BC})$ is the most common malignant tumor and the highest cause of cancer-related deaths in women

Correspondence to: Dr Mitsuro Kanda, Department of Gastroenterological Surgery (Surgery II), Nagoya University Graduate School of Medicine, 65 Tsurumai-cho, Showa-ku, Nagoya 466-8550, Japan

E-mail:m-kanda@med.nagoya-u.ac.jp

Key words: breast cancer, DERL3, expression, progression, biomarker world-wide (1). Because of the development of adjuvant medication therapy such as chemotherapy, endocrine therapy and anti-human epidermal growth factor 2 (HER2) therapy, prognosis of BC patients has improved (2). The 5-, 10- and 15-year relative survival rates are 89,83 and $78 \%$, respectively (3). However, recurrent $\mathrm{BC}$ after resection is still difficult to cure (4). Therefore, development of novel molecular targets is still required. Several commercial multigene expression assays are available (5). Although they can help evaluate prognosis and appropriateness of adjuvant chemotherapy, additional informative biomarkers may improve their accuracy.

Derlin3 (DERL3) gene is located at 22q11.23; its protein locates in the endoplasmic reticulum (EnRt). It belongs to the Derlin family (DERL1, DERL2 and DERL3), which mediates endoplasmic reticulum-associated degradation (ERAD) of misfolded proteins, one of the EnRt stress responses (6-9). Reportedly, EnRt stress responses contribute to cancer progression $(10,11)$. Although DERLl overexpression is reported in BC (12), colon cancer (13) and non-small cell lung cancer (NSCLC) (14), no studies have addressed the role of DERL3 in BC. Referring to EnRt stress responses in $\mathrm{BC}$, previous studies demonstrate that GRP78, an EnRt chaperone (15), is overexpressed in high-grade BC (16) and $X B P-1$, a UPR-related transcription factor, is overexpressed in BC (17). The relationship between DERL3 and these molecules remains elusive.

In searching for a new therapeutic target that is overexpressed in $\mathrm{BC}$, we chose DERL3 as a candidate. This study therefore investigated $D E R L 3$ expression and functions to determine whether DERL3 is a potential biomarker and therapeutic target for $\mathrm{BC}$.

\section{Materials and methods}

Sample collection. We obtained 13 human $\mathrm{BC}$ cell lines (BT-20, BT-474, BT-549, HCC1419, HCC1954, Hs578T, MCF7, MDA-MB-231, MDA-MB-361, MDA-MB-415, MDA-MB-468, SK-BR-3, and ZR-75-1) and two noncancerous breast epithelial cell lines (MCF-10A, and MCF-12A). BT-549, HCC1419, HCC1954, and Hs578T were purchased from Japanese Collection of Research Bioresources 
Cell Bank (Osaka, Japan), BT-474, MCF-7, and MCF-12A were kindly provided by Dr David Sidransky, the Director of the Department of Otolaryngology-Head and Neck Surgery of Johns Hopkins University (Baltimore, MD, USA), and others were from the American Type Culture Collection (Manassas, VA, USA). Cells were stored at $-80^{\circ} \mathrm{C}$ using cell-preservative solution (Cell Banker; Mitsubishi Chemical Medience Corporation, Tokyo, Japan) and cultured in RPMI-1640 (Sigma-Aldrich, St. Louis, MO, USA) supplemented with $10 \%$ fetal bovine serum (FBS), in an atmosphere containing 5\% $\mathrm{CO}_{2}$ at $37^{\circ} \mathrm{C}(18,19)$.

We acquired 167 primary $\mathrm{BC}$ specimens from patients who underwent breast surgery at Nagoya University Hospital between March 2002 and November 2009. All specimens were diagnosed histologically as BC, frozen immediately after resection, and stored at $-80^{\circ} \mathrm{C}$. Adjacent non-cancerous specimens were resected $>3 \mathrm{~cm}$ from the tumor edges. $\mathrm{BC}$ specimens were classified histologically using the Union for International Cancer Control (UICC) staging system for BC (7th edition). Selected patients received adjuvant chemotherapy, endocrine therapy and anti-HER2 therapy, according to their conditions, pathological factors and physicians' discretion. Patient followup data and clinicopathological parameters were collected from medical records.

This study conforms to the ethical guidelines of the Declaration of Helsinki. Enrollees granted written informed consent for use of clinical samples and data, as required by our institutional review board.

Quantitative real-time reverse-transcription polymerase chain reaction ( $q R T-P C R)$. DERL3 mRNA expression was determined by qRT-PCR. We extracted RNA from cell lines (8.0x10 6 cells per each cell line), 167 primary BCs, and adjacent normal tissues using the RNeasy mini kit (Qiagen, Hilden, Germany) according to the manufacturer's protocol. cDNA was synthesized from total RNAs $(1 \mu \mathrm{g})$ by M-MLV Reverse Transcriptase (Invitrogen, Frederick, MD, USA) and Primer 'random' (Sigma-Aldrich). The qRT-PCR of DERL3, GRP78 and $X B P 1$ was performed using the SYBR Green PCR Core Reagents kit (Applied Biosystems) as follows: 1 cycle of $95^{\circ} \mathrm{C}$ $(10 \mathrm{~min}) ; 40$ cycles of $95^{\circ} \mathrm{C}(5 \mathrm{sec})$, and $60^{\circ} \mathrm{C}(60 \mathrm{sec})$. The primers specific for each gene were as follows: DERL3: forward 5'-CTCACTTTCCAGGCACCGT-3'and reverse 5'-TAGTAGATATGGCCCACCGC-3', which generated a 110-bp product; GRP78: forward 5'-GACATCAAGTTCTTG CCGTT-3' and reverse 5'-CTCATAACATTTAGGCCAGC-3', which generated a 260-bp product (20); and XBP1: forward 5'-CAGACTACGTGCGCCTCTGC-3' and reverse 5'-CTTC TGGGTAGACCTCTGGG-3', which generated a 208-bp product (21). Glyceraldehyde-3-phosphate dehydrogenase (GAPDH) mRNA levels were quantified to normalize expression levels. Each sample was tested in triplicate; data are shown as (DERL3 value)/(GAPDH value) $(22,23)$.

Inhibiting DERL3 expression by DERL3-specific small interfering RNAs (siRNAs). Four kinds of siRNAs specific for DERL3 (siDERL3) were used to transfect BT-549 cells. Their sequences were siDERL3-1: 5'-GAUUCAGCUUCUUCU UCAATT-3'; siDERL3-2: 5'-UUGAAGAAGAAGCUGAAU CCCAGGGTT-3' (from a previous study) (24); siDERL3-3:
5'-UUGAAGUAGAGUUGAAAGGGG-3'; and siDERL3-4: 5'-UGAAGAAGAAGCUGAAUCCCA-3' (Hokkaido System Science, Sapporo, Japan). AccuTarget Negative Control siRNA Fluorescein-labeled (siControl; Cosmo Bio Co. Ltd., Tokyo, Japan) served as control nontargeting siRNA. The BC cells were seeded into $10-\mathrm{cm}$ dishes with $10 \mathrm{ml}$ of antibiotic-free RPMI-1640 with 10\% FBS, and transfected with 400 pmol of siControl or siDERL3s in the presence of 40- $\mu 1$ LipoTrust EX Oligo (Hokkaido System Science) $24 \mathrm{~h}$ after seeding. After transfection, cells were cultured in antibiotic-free RPMI-1640 with $10 \%$ FBS for $72 \mathrm{~h}$.

Western blotting. Cells were incubated in RIPA lysis buffer; lysates were stored at $-30^{\circ} \mathrm{C}$. Total protein lysates $(20 \mu \mathrm{g} / \mathrm{well})$ were electrophoretically transferred onto polyvinylidene difluoride membranes that were blocked using 5\% skim milk in $0.05 \%$ PBS-T, and incubated at $4^{\circ} \mathrm{C}$ overnight with rabbit anti-DERL3 polyclonal antibody (1:500; Abcam, Cambridge, UK). The membrane was then washed and probed with an anti-rabbit secondary antibody conjugated to horseradish peroxidase (Cell Signaling Technology, Beverly, MA, USA). $\beta$-actin served as endogenous control (25).

Proliferation assay. Proliferation was evaluated using Cell Counting Kit-8 (CCK-8) (Dojindo Molecular Technologies, Inc., Kumamoto, Japan). After transfection with siDERL3 (mixture of siDERL3-1, -2, -3 and -4), BT-549 cells (5x103/well) were seeded into 96-well plates with RPMI-1640 containing $2 \%$ FBS. Optical density of each well was measured 5 days after seeding, $2 \mathrm{~h}$ after adding $10 \mu \mathrm{l}$ of CCK-8 solution.

Invasiveness assay. Invasiveness in Matrigel was determined using BioCoat Matrigel Invasion Chambers (Corning Inc., Corning, NY, USA) according to manufacturer's protocol. After transfection with mixed siDERL3s, BT-549 cells $\left(2.5 \times 10^{4} /\right.$ well $)$ were suspended in serum-free RPMI-1640 and seeded in upper chambers. After $60 \mathrm{~h}$ of incubation, cells on membrane surfaces were fixed, stained, and counted in ten randomly selected microscope fields.

Migration assay. Migration of BT-549 cells was determined using a wound-healing assay. After transfection with mixed siDERL3s, BT-549 cells ( $3 \times 10^{4} /$ well) were seeded into each well of a 35-mm dish with culture insert (Ibidi, Martinsried, Germany) in RPMI-1640 containing 2\% FBS. After $24 \mathrm{~h}$, the insert was removed, and wound widths were measured at $100-\mu \mathrm{m}$ intervals (20 measurements/well, x40 magnification) at cell-dependent time intervals.

Statistical analysis. Differences in DERL3 mRNA expression between two groups were evaluated using Mann-Whitney test. Correlations between DERL3 mRNA levels and those of GRP78 and XBP1 were analyzed using the Spearman's rank correlation test. Significance of associations between DERL3 mRNA expression and clinicopathological parameters was analyzed with $\chi^{2}$ test. Overall survival (OS) and disease-free survival (DFS) were calculated using Kaplan-Meier method; differences in survival curves were evaluated by log-rank tests. Multivariate regression analysis used Cox proportional hazards model to identify prognostic factors; variables for 

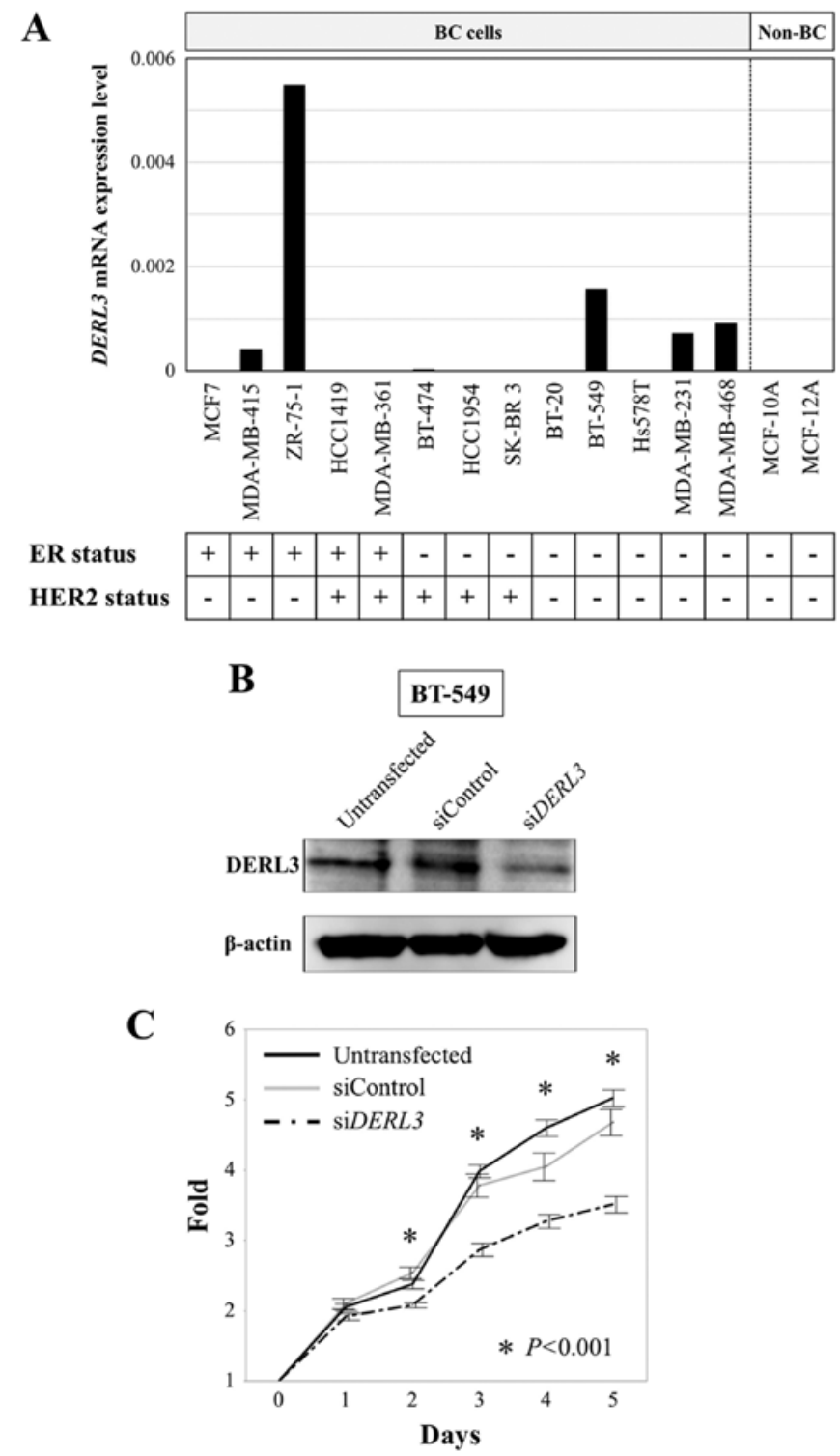

Figure 1. (A) DERL3 mRNA expression in breast cancer and non-cancerous cells. DERL3 mRNA expression was detectable in MDA-MB-415, ZR-75-1, BT-549, MDA-MB-231, and MDA-MB-468 cells, but not in other tested cell lines. BC cells, breast cancer cell lines. Non-BC, non-cancerous cell lines. (B) Western blotting confirmed inhibition of siDERL3s in transfected cells (C) siDERL3-transfected BT-549 cells showed significantly lower proliferation after 2 days than untransfected and control cells. ${ }^{*} \mathrm{P}<0.001$.

which $\mathrm{P}<0.05$ were entered into the final model. All statistical analyses were performed on JMP 12 software (SAS Institute Inc., Cary, NC, USA). $\mathrm{P}<0.05$ was considered to indicate a statistically significant difference.

\section{Results}

DERL3 $m R N A$ expression in BC and non-cancerous cell lines. $D E R L 3$ mRNA expression was detectable in five $\mathrm{BC}$ cell lines (38\%), but not in other BC cell lines or non-cancerous cell lines (Fig. 1A). In BC cell lines, DERL3 mRNA expression did not differ between estrogen receptor (ER) positive and ER negative, HER2 positive and HER2 negative, or triple-negative and other subtypes. ER and HER2 status of the cell lines were evaluated in previous studies $(26,27)$.
Table I. Associations between DERL3 mRNA expression and clinicopathological characteristics of 167 patients with breast cancer.

\begin{tabular}{|c|c|c|c|}
\hline $\begin{array}{l}\text { Clinicopathological } \\
\text { parameter }\end{array}$ & $\begin{array}{l}\text { High DERL3 } \\
\text { group }(\mathrm{n}=42)\end{array}$ & $\begin{array}{l}\text { Others } \\
(\mathrm{n}=125)\end{array}$ & $\mathrm{P}$-value $\mathrm{a}^{\mathrm{a}}$ \\
\hline Age & & & 0.065 \\
\hline$\leq 60$ year & 32 & 76 & \\
\hline$>60$ year & 10 & 49 & \\
\hline Histology & & & 0.265 \\
\hline DCIS & 0 & 7 & \\
\hline IDC & 39 & 109 & \\
\hline ILC & 2 & 4 & \\
\hline Others & 1 & 5 & \\
\hline UICC T factor & & & 0.207 \\
\hline Tis & 0 & 7 & \\
\hline $\mathrm{T} 1$ & 18 & 52 & \\
\hline $\mathrm{T} 2$ & 19 & 56 & \\
\hline T3 & 4 & 5 & \\
\hline $\mathrm{T} 4$ & 1 & 5 & \\
\hline Node status & & & 0.054 \\
\hline Negative & 16 & 69 & \\
\hline Positive & 26 & 56 & \\
\hline UICC pathological stage & & & 0.211 \\
\hline 0/I/II & 30 & 101 & \\
\hline III/IV & 12 & 24 & \\
\hline ER status & & & 0.424 \\
\hline Positive & 30 & 97 & \\
\hline Negative & 12 & 28 & \\
\hline PgR status & & & 0.062 \\
\hline Positive & 24 & 91 & \\
\hline Negative & 18 & 34 & \\
\hline HER2 status & & & 0.792 \\
\hline Positive & 11 & 28 & \\
\hline Negative & 31 & 88 & \\
\hline Unknown & 0 & 9 & \\
\hline Triple-negative & & & 0.800 \\
\hline True & 5 & 13 & \\
\hline False & 37 & 111 & \\
\hline Unknown & 0 & 1 & \\
\hline Adjuvant therapy & & & 0.460 \\
\hline Endocrine therapy alone & 13 & 44 & \\
\hline Chemotherapy alone & 11 & 19 & \\
\hline Endocrine and chemotherapy & 15 & 49 & \\
\hline None & 3 & 13 & \\
\hline
\end{tabular}

${ }^{\mathrm{a}} \chi^{2}$ test. DCIS, ductal carcinoma in situ; IDC, invasive ductal carcinoma; ILC, invasive lobular carcinoma; UICC, Union for International Cancer Control; Tis, carcinoma in situ; ER, estrogen receptor; PgR, progesterone receptor; HER2, human epidermal growth factor 2. 

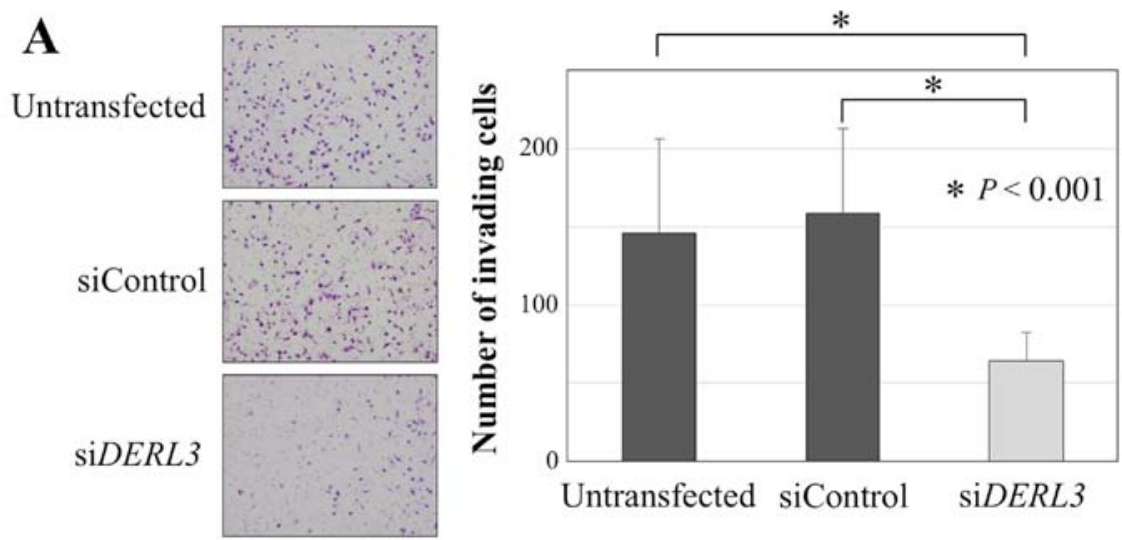

B

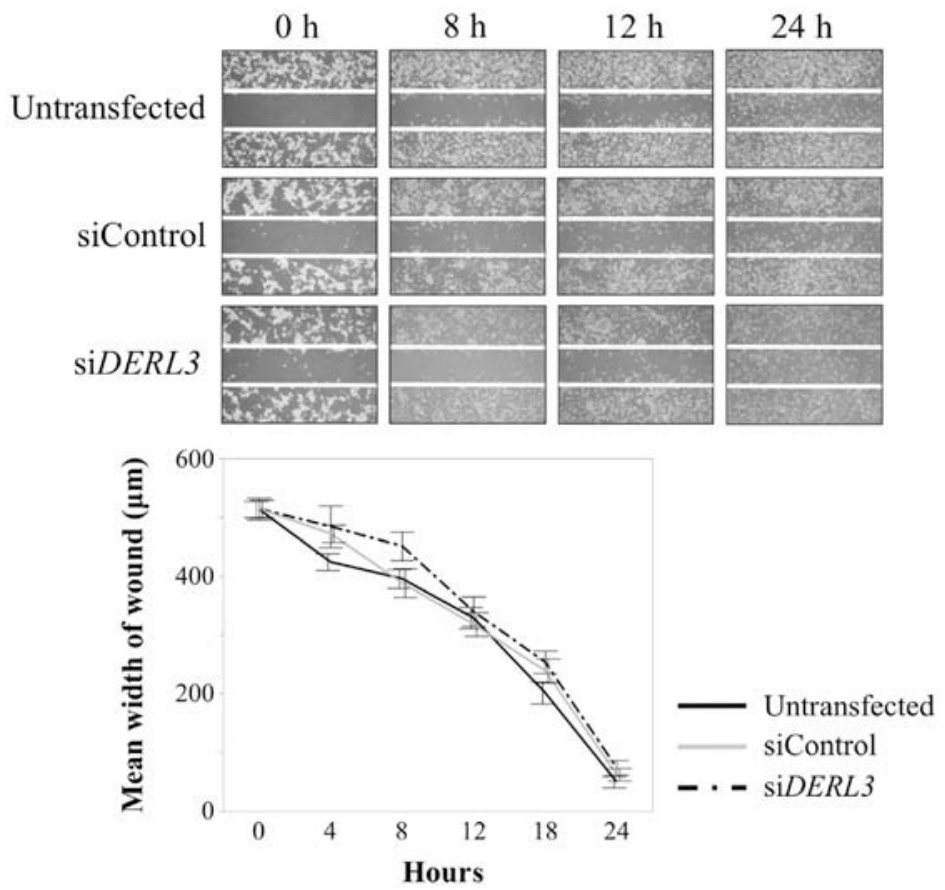

Figure 2. (A) Invasiveness assay: inhibiting DERL3 expression in BT-549 cells significantly decreased numbers of invading cells. ${ }^{*} \mathrm{P}<0.001$. (B) Migration assay: there were no significant differences.

Expression analysis of DERL3 and genes encoding putative functional partners in BC cell lines. We evaluated the correlation between DERL3 mRNA expression levels and the genes $G R P 78$ and XBP1 that could potentially functionally interact with DERL3. There were no correlations between DERL3 and GRP78 mRNA expression levels (correlation coefficient 0.253, $\mathrm{P}=0.405$ ). Although it was not statistically significant, we found a weak correlation between DERL3 and XBP1 mRNA expression levels (correlation coefficient $0.335, \mathrm{P}=0.263$ ).

Effects of DERL3 inhibition on BC cell phenotypes. BT-549 cell line was transfected with siDERL3s to determine DERL3 functions in BC. Western blot analysis confirmed that DERL3 was decreased by the transfections (Fig. 1B). We evaluated proliferation, invasion, and migration. DERL3 inhibition significantly decreased proliferation over days 2-5 compared with the untransfected and siControl cells $(\mathrm{P}<0.001$; Fig. 1C). In the invasion assay, significantly fewer $D E R L 3$-inhibited cells invaded the Matrigel than did untransfected and siControl cells $(\mathrm{P}<0.001 ;$ Fig. 2A). In contrast, there was no difference in the migration assay (Fig. 2B).

Patient characteristics. All 167 patients were women, whose mean age was $54.4 \pm 11.6$ years (range: $26-78$ years); and whose disease stages were stage 0: 7; stage I: 47; stage II: 78; stage III: 34; and stage IV: 1 . Their median follow-up period was 100.0 months (range: 8-155 months) or until death.

DERL3 mRNA expression levels did not differ significantly between $\mathrm{BC}$ tissues and adjacent non-cancerous tissues $(\mathrm{P}=0.125)$. DERL3 mRNA expression levels were higher in $\mathrm{BC}$ tissues than in adjacent non-cancerous tissues for 94 (56.3\%) of the 167 patients. Of note, DERL3 mRNA expression levels for several $\mathrm{BC}$ specimens were as low as their non-cancerous counterparts, whereas some $\mathrm{BC}$ specimens did express high DERL3 mRNA levels.

Clinical and prognostic significance of DERL3 $m R N A$ expression in BC specimens. Among the 167 patients, we found 
A
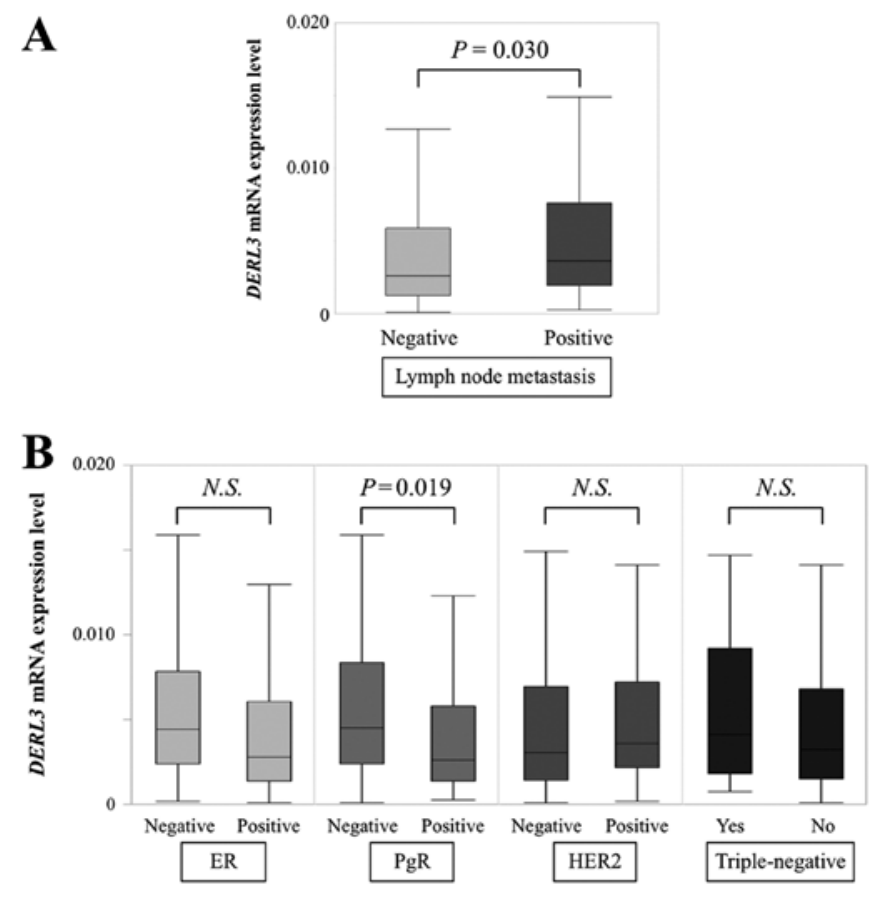

C

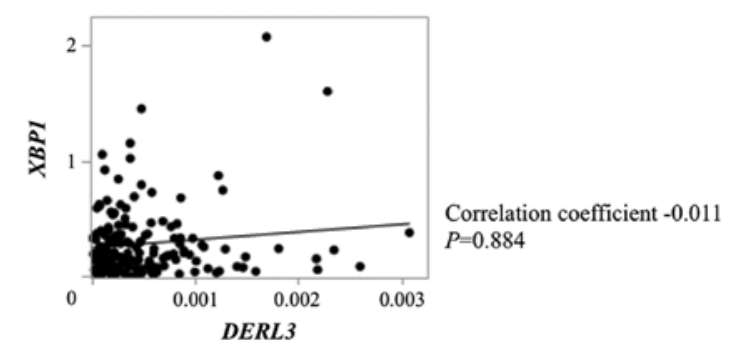

Figure 3. DERL3 mRNA expression was significantly higher (A) in LN metastasis-positive specimens than in LN metastasis-negative specimens; and (B) in PgR-negative specimens than in PgR-positive specimens. (C) Correlations of mRNA expression levels between DERL3 and XBP1 in BC specimens.

DERL3 mRNA expression to be significantly higher in those with lymph node $(\mathrm{LN})$ metastasis $(\mathrm{n}=82)$ than in those without LN metastasis ( $\mathrm{n}=85 ; \mathrm{P}=0.030$; Fig. 3A). DERL3 expression did not differ with regard to $\mathrm{T}$ categories or UICC stage. Among conventional biomarkers (Fig. 3B), DERL3 mRNA expression in progesterone receptor (PgR)-negative specimens $(n=52)$ was significantly higher than in PgR-positive specimens $(n=115$; $\mathrm{P}=0.019)$. There were not significant differences between ER-positive $(n=127)$ and -negative $(n=40 ; P=0.070)$, HER2positive $(n=39)$ and -negative $(n=119 ; P=0.577$; missing data for 9 patients), or triple-negative $(n=18)$ and non-triple-negative specimens ( $\mathrm{n}=148 ; \mathrm{P}=0.467$; missing data for 1 patient). We evaluated the correlation between DERL3 mRNA levels and $X B P 1$ mRNA levels in the patients' BC specimens. There were no correlations between mRNA expression levels of these genes (correlation coefficient $-0.011, \mathrm{P}=0.884$; Fig. 3C).

The patients with the highest quartile of DERL3 expression were designated as 'high DERL3 group' ( $\mathrm{n}=42)$, and the remaining patients were designated as 'others' $(n=125)$. We found no significant differences with regard to any tested clinicopathological characteristics (Table I). The high DERL3 group experienced significantly shorter OS than others (5-year
A

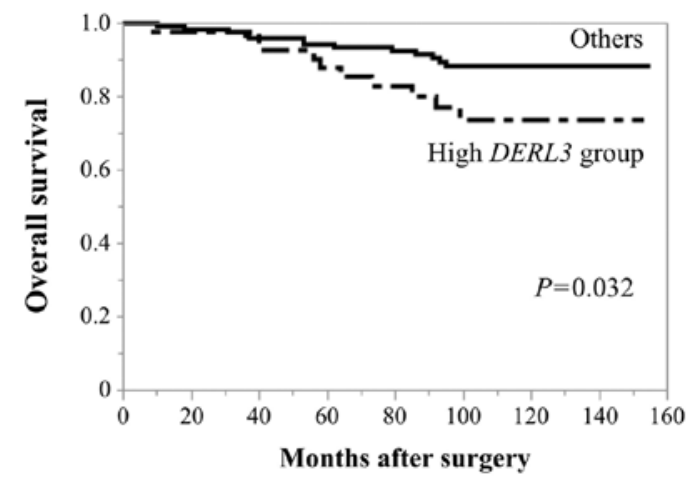

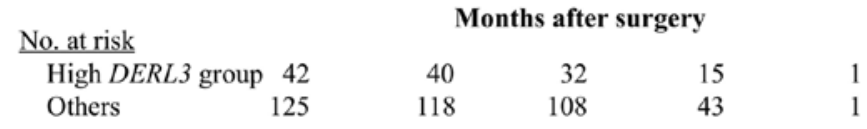

B

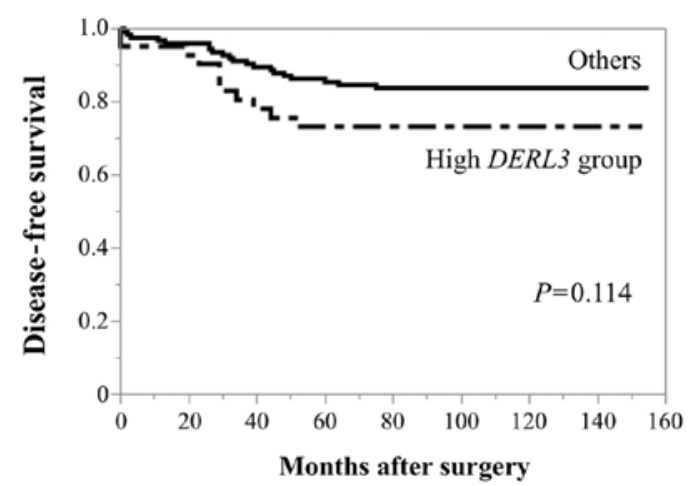

No. at risk

High DERL3 group 42

Others

125

33

29

15

41

Figure 4. (A) Patients of high DERL3 group experienced significantly shorter overall survival than others. (B) High DERL3 group tended to have shorter disease-free survival than others, although the difference was not statistically significant.

OS, high DERL3 group: $87.9 \%$; others: $94.3 \%$; $\mathrm{P}=0.032$; Fig. 4A). Moreover, high DERL3 group tended to have poorer DFS than others, although there were no statistically significant differences (5-year DFS, high DERL3 group: $73.3 \%$; others: $85.4 \%$; $\mathrm{P}=0.114$; Fig. $4 \mathrm{~B}$ ).

Multivariate analysis of OS identified UICC pathological stage III/IV disease (HR: 6.43; 95\% CI: 2.26-20.3, P<0.001) as an independent prognostic factor, but not high DERL3 expression (HR: 2.27; 95\% CI: 0.92-5.47, $\mathrm{P}=0.074$; Table II).

\section{Discussion}

In this study, we showed that DERL3 promotes BC cell proliferation and invasiveness, and that high DERL3 patients experienced poorer prognosis.

When cells undergo stress through hypoxia and nutrient deprivation, misfolded proteins increase, and activate the unfolded protein response (UPR) $(11,28)$, which upregulates ERAD, and contributes to progression in cancer cells $(10,11)$. Reportedly, GRP78, an EnRt chaperone (15), is overexpressed in high-grade BC (16). Furthermore, XBP-1, a UPR-related transcription factor, is overexpressed in $\mathrm{BC}$, but is hardly detectable in non-cancerous breast tissues (17). These findings suggest that UPR promotes a malignant BC phenotype. 
Table II. Prognostic factors for overall survival in 167 patients with breast cancer.

\begin{tabular}{|c|c|c|c|c|c|c|c|}
\hline \multirow[b]{2}{*}{ Variables } & \multirow[b]{2}{*}{$\mathrm{n}$} & \multicolumn{3}{|c|}{ Univariate } & \multicolumn{3}{|c|}{ Multivariate } \\
\hline & & Hazard ratio & $95 \% \mathrm{CI}$ & P-value & Hazard ratio & $95 \% \mathrm{CI}$ & P-value \\
\hline Age $(\leq 60)$ & 108 & 1.17 & $0.50-3.03$ & 0.733 & & & \\
\hline UICC pathological stage (III/IV) & 36 & 7.65 & $3.35-18.4$ & $<0.001$ & 6.43 & $2.26-20.3$ & $<0.001^{\mathrm{a}}$ \\
\hline ER status (negative) & 40 & 2.43 & $1.01-5.54$ & 0.047 & 2.34 & $0.52-17.5$ & 0.279 \\
\hline PgR status (negative) & 52 & 2.32 & $1.01-5.30$ & 0.048 & 0.95 & $0.14-3.74$ & 0.951 \\
\hline HER2 status (positive) & 39 & 2.76 & $1.16-6.40$ & 0.022 & 1.14 & $0.38-3.32$ & 0.815 \\
\hline Triple-negative (yes) & 18 & 2.23 & $0.65-5.95$ & 0.183 & & & \\
\hline Adjuvant chemotherapy (yes) & 94 & 3.11 & $1.24-9.43$ & 0.002 & 0.82 & $0.23-2.99$ & 0.751 \\
\hline High DERL3 expression & 42 & 2.40 & $1.02-5.45$ & 0.044 & 2.27 & $0.92-5.47$ & 0.074 \\
\hline
\end{tabular}

${ }^{\mathrm{a}} \mathrm{P}<0.05$. Univariate analysis: log-rank test. Multivariate analysis: Cox proportional hazards model. CI, confidence interval; UICC, Union for International Cancer Control; ER, estrogen receptor; PgR, progesterone receptor; HER2, human epidermal growth factor 2.

DERL1 is the most widely studied derlin (6), and regulated by the IRE-XBP1 pathway $(8,29)$. Its overexpression reportedly prevents induction of apoptosis in stressed BC cells and correlates with advanced pathological tumor grade and node-positive status in BC (12). It also contributes to malignant phenotype in colon cancer and in NSCLC by activating the PI3K/AKT and EGRF-EPK pathways, respectively $(13,14)$.

There have been only a few studies on DERL3. Although $D E R L 3$ is assumed to be regulated by IRE1-XBP1 pathway such as DERL1 (8), no significant correlations were found between $D E R L 3$ and $X B P 1$ mRNA expression levels. There might be another pathway that regulates the expression of DERL3 in BC cells. According to previous studies, DERL3 has a protective function for cardiomyocytes through the ERAD mechanism (30), and low DERL3 expression has been associated with a more malignant phenotype and poorer prognosis in colorectal cancer (31). We have shown that DERL3 mRNA is scarcely expressed not only in non-cancerous breast cell lines but also in several BC cell lines along with a considerable proportion of $\mathrm{BC}$ specimens. These findings suggest that both non-cancerous breast cells and BC cells express little DERL3 mRNA under slight EnRt stress.

DERL3 inhibition significantly decreased BC cell proliferation and invasion, and patients with high DERL3 group tended to be $\mathrm{LN}$ metastasis-positive $(\mathrm{P}=0.054$; Table I). These results indicate that $D E R L 3$ does promote malignant phenotype when overexpressed in BC. Noteworthy, DERL1 mRNA overexpression also correlates with positive LN metastasis in BC, colon cancer and NSCLC by the inhibition of apoptosis and the activation of PI3K/AKT, EGRF-EPK pathways, respectively (12-14). DERL3 might regulate such mechanisms in $\mathrm{BC}$, and it promotes LN metastasis, leading to more malignant phenotype. Further studies are required to determine the underlying mechanisms. We found that the high DERL3 group experienced shorter OS, independently of ER, PgR and HER2 status, which implies its potential as a prognostic biomarker for all BC subtypes.

These findings have several possible clinical applications. DERL3 levels in resected samples can help predict prognosis. Patients with high DERL3 specimens may require more aggressive adjuvant therapy; and if DERL3 mRNA expression levels can be determined from pre-surgical biopsies, they might help indicate whether neoadjuvant therapy is appropriate. Although further studies are warranted, our study suggests the possibility of developing new therapies for $\mathrm{BC}$ that target DERL3.

This study has some limitations. First, the roles of DERL3 in the ERAD pathway of cancer cells, and of ERAD in BC, are unclear. Pathway analyses might elucidate the role of DERL3 in UPR. Second, interventions such as adjuvant medication might have affected relationships between patient DERL3 mRNA levels and prognoses. Finally, these results were obtained from in vitro data and should be verified by in vivo studies.

In conclusion, we found DERL3 to promote a malignant BC phenotype. High DERL3 mRNA expression in the BC tissue resulted in poor prognosis. DERL3 mRNA expression is a potential prognostic marker and $D E R L 3$ protein could be a candidate therapeutic target for $\mathrm{BC}$.

\section{References}

1. Jemal A, Center MM, DeSantis C and Ward EM: Global patterns of cancer incidence and mortality rates and trends. Cancer Epidemiol Biomarkers Prev 19: 1893-1907, 2010.

2. Giordano SH, Buzdar AU, Smith TL, Kau SW, Yang Y and Hortobagyi GN: Is breast cancer survival improving? Cancer 100: 44-52, 2004.

3. Miller KD, Siegel RL, Lin CC, Mariotto AB, Kramer JL, Rowland JH, Stein KD, Alteri R and Jemal A: Cancer treatment and survivorship statistics, 2016. CA Cancer J Clin 66: 271-289, 2016.

4. Iwata H: Future treatment strategies for metastatic breast cancer: Curable or incurable? Breast Cancer 19: 200-205, 2012.

5. Coates AS, Winer EP, Goldhirsch A, Gelber RD, Gnant M, Piccart-Gebhart M, Thürlimann B and Senn HJ; Panel Members: Tailoring therapies - improving the management of early breast cancer: St Gallen International Expert Consensus on the Primary Therapy of Early Breast Cancer 2015. Ann Oncol 26: 1533-1546, 2015.

6. Greenblatt EJ, Olzmann JA and Kopito RR: Derlin-1 is a rhomboid pseudoprotease required for the dislocation of mutant $\alpha-1$ antitrypsin from the endoplasmic reticulum. Nat Struct Mol Biol 18: 1147-1152, 2011.

7. Lilley BN and Ploegh HL: A membrane protein required for dislocation of misfolded proteins from the ER. Nature 429: 834-840, 2004 
8. Oda Y, Okada T, Yoshida H, Kaufman RJ, Nagata K and Mori K Derlin-2 and Derlin-3 are regulated by the mammalian unfolded protein response and are required for ER-associated degradation. J Cell Biol 172: 383-393, 2006.

9. Ye Y, Shibata Y, Yun C, Ron D and Rapoport TA: A membrane protein complex mediates retro-translocation from the ER lumen into the cytosol. Nature 429: 841-847, 2004.

10. Cox JS, Shamu CE and Walter P: Transcriptional induction of genes encoding endoplasmic reticulum resident proteins requires a transmembrane protein kinase. Cell 73: 1197-1206, 1993.

11. Koumenis C: ER stress, hypoxia tolerance and tumor progression. Curr Mol Med 6: 55-69, 2006.

12. Wang J, Hua H, Ran Y, Zhang H, Liu W, Yang Z and Jiang Y: Derlin-1 is overexpressed in human breast carcinoma and protects cancer cells from endoplasmic reticulum stress-induced apoptosis. Breast Cancer Res 10: R7, 2008.

13. Tan X, He X, Jiang Z, Wang X, Ma L, Liu L, Wang X, Fan Z and Su D: Derlin-1 is overexpressed in human colon cancer and promotes cancer cell proliferation. Mol Cell Biochem 408: 205-213, 2015

14. Dong QZ, Wang Y, Tang ZP, Fu L, Li QC, Wang ED and Wang EH: Derlin-1 is overexpressed in non-small cell lung cancer and promotes cancer cell invasion via EGFR-ERKmediated up-regulation of MMP-2 and MMP-9. Am J Pathol 182: 954-964, 2013

15. Li J and Lee AS: Stress induction of GRP78/BiP and its role in cancer. Curr Mol Med 6: 45-54, 2006.

16. Fernandez PM, Tabbara SO, Jacobs LK, Manning FC, Tsangaris TN, Schwartz AM, Kennedy KA and Patierno SR: Overexpression of the glucose-regulated stress gene GRP78 in malignant but not benign human breast lesions. Breast Cancer Res Treat 59: 15-26, 2000.

17. Fujimoto T, Onda M, Nagai H, Nagahata T, Ogawa K and Emi M: Upregulation and overexpression of human X-box binding protein 1 (hXBP-1) gene in primary breast cancers. Breast Cancer 10: 301-306, 2003.

18. Kanda M, Shimizu D, Fujii T, Tanaka H, Shibata M, Iwata N, Hayashi M, Kobayashi D, Tanaka C, Yamada S, et al: Protein arginine methyltransferase 5 is associated with malignant phenotype and peritoneal metastasis in gastric cancer. Int J Oncol 49: 1195-1202, 2016.

19. Kanda M, Shimizu D, Nomoto S, Takami H, Hibino S, Oya H, Hashimoto R, Suenaga M, Inokawa Y, Kobayashi D, et al: Prognostic impact of expression and methylation status of DENN/MADD domain-containing protein 2D in gastric cancer. Gastric Cancer 18: 288-296, 2015.

20. Xing X, Li Y, Liu H, Wang L and Sun L: Glucose regulated protein 78 (GRP78) is overexpressed in colorectal carcinoma and regulates colorectal carcinoma cell growth and apoptosis. Acta Histochem 113: 777-782, 2011

21. Szegezdi E, Duffy A, O'Mahoney ME, Logue SE, Mylotte LA, O'brien T and Samali A: ER stress contributes to ischemiainduced cardiomyocyte apoptosis. Biochem Biophys Res Commun 349: 1406-1411, 2006.
22. Kanda M, Nomoto S, Oya H, Takami H, Shimizu D, Hibino S, Hashimoto R, Kobayashi D, Tanaka C, Yamada S, et al: The expression of melanoma-associated antigen D2 both in surgically resected and serum samples serves as clinically relevant biomarker of gastric cancer progression. Ann Surg Oncol 23 (Suppl 2): S214-S221, 2016.

23. Kanda M, Shimizu D, Fujii T, Sueoka S, Tanaka Y, Ezaka K, Takami H, Tanaka H, Hashimoto R, Iwata N, et al: Function and diagnostic value of Anosmin-1 in gastric cancer progression. Int J Cancer 138: 721-730, 2016.

24. Kadowaki H, Nagai A, Maruyama T, Takami Y, Satrimafitrah P, Kato H, Honda A, Hatta T, Natsume T, Sato T, et al: Pre-emptive quality control protects the ER from protein overload via the proximity of ERAD components and SRP. Cell Rep 13: 944-956, 2015.

25. Oya H, Kanda M, Sugimoto H, Shimizu D, Takami H, Hibino S, Hashimoto R, Okamura Y, Yamada S, Fujii T, et al: Dihydropyrimidinase-like 3 is a putative hepatocellular carcinoma tumor suppressor. J Gastroenterol 50: 590-600, 2015.

26. Finn RS, Dering J, Conklin D, Kalous O, Cohen DJ, Desai AJ, Ginther C, Atefi M, Chen I, Fowst C, et al: PD 0332991, a selective cyclin D kinase 4/6 inhibitor, preferentially inhibits proliferation of luminal estrogen receptor-positive human breast cancer cell lines in vitro. Breast Cancer Res 11: R77, 2009.

27. Subik K, Lee JF, Baxter L, Strzepek T, Costello D, Crowley P, Xing L, Hung MC, Bonfiglio T, Hicks DG, et al: The expression patterns of ER, PR, HER2, CK5/6, EGFR, Ki-67 and AR by immunohistochemical analysis in breast cancer cell lines. Breast Cancer (Auckl) 4: 35-41, 2010.

28. Hochachka PW, Buck LT, Doll CJ and Land SC: Unifying theory of hypoxia tolerance: Molecular/metabolic defense and rescue mechanisms for surviving oxygen lack. Proc Natl Acad Sci USA 93: 9493-9498, 1996.

29. Lilley BN and Ploegh HL: Multiprotein complexes that link dislocation, ubiquitination, and extraction of misfolded proteins from the endoplasmic reticulum membrane. Proc Natl Acad Sci USA 102: 14296-14301, 2005

30. Belmont PJ, Chen WJ, San Pedro MN, Thuerauf DJ, Gellings Lowe N, Gude N, Hilton B, Wolkowicz R, Sussman MA and Glembotski CC: Roles for endoplasmic reticulum-associated degradation and the novel endoplasmic reticulum stress response gene Derlin-3 in the ischemic heart. Circ Res 106: 307-316, 2010.

31. Lopez-Serra P, Marcilla M, Villanueva A, Ramos-Fernandez A, Palau A, Leal L, Wahi JE, Setien-Baranda F, Szczesna K, Moutinho C, et al: A DERL3-associated defect in the degradation of SLC2A1 mediates the Warburg effect. Nat Commun 5: 3608, 2014. 